\title{
Characteristics, treatments, and outcomes among patients with abdominal aortic injury in Japan: a nationwide cohort study
}

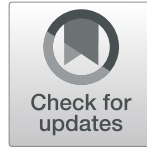

Yutaka Kondo $^{1,2^{*}}$, Hiroki Matsui ${ }^{1}$ and Hideo Yasunaga ${ }^{1}$

\begin{abstract}
Background: Abdominal aortic injury (AAl) is a life-threatening condition that occurs in only $0.1 \%$ of all trauma admissions. Because of its rarity, the clinical features of AAl remain unclear. We investigated the characteristics, treatments, and clinical outcomes among patients with AAl.

Methods: This retrospective cohort study was performed using the Japanese Diagnosis Procedure Combination database. We identified patients with a confirmed diagnosis of AAl with emergency admission from 1 July 2010 to 31 March 2017. Eligible patients were divided into three groups: those who were treated with no surgery or endovascular treatment (nonrepair group), those who underwent surgery without endovascular treatment (open repair group), and those who received endovascular treatment without surgery (endovascular repair group).

Results: A total of 238 patients met the inclusion criteria during the study period. Of these, 191 (80.3\%) were allocated to the non-repair group, 20 (8.4\%) were allocated to the open repair group, and 27 (11.3\%) were allocated to the endovascular repair group. The proportions of patients in the non-repair group from July 2010 to March 2012, April 2012 to March 2014, April 2014 to March 2016, and April 2016 to March 2017 were 93.5\%, 75.9\%, 80.6\%, and 73.2\%, respectively. The crude in-hospital mortality rate was $26.2 \%, 35.0 \%$, and $18.5 \%$ in the non-repair, open repair, and endovascular repair group, respectively.
\end{abstract}

Conclusions: In this cohort, the proportion of non-repair for AAI decreased from 2010 to 2017, whereas the proportion of endovascular repair increased. Younger patients were more likely to undergo open repair, whereas older patients were more likely to undergo endovascular repair.

Keywords: Abdominal aortic injury, Epidemiology, Trauma, Emergency departments

\section{Background}

Abdominal aortic injury (AAI) is a life-threatening condition. Surgery (open repair) is the standard treatment for bleeding control. AAI occurs in only $0.1 \%$ of all trauma admissions and at approximately one fifth the frequency of thoracic aortic injury [1]. Data regarding AAI are mostly based on case reports. Two cohort studies demonstrated that the overall mortality rates among patients with AAI were $35 \%$ and $51.7 \%$ [2, 3]. Because of its rarity, the clinical features of AAI remain unknown.

\footnotetext{
* Correspondence: kondokondou2000@yahoo.co.jp

1 Department of Clinical Epidemiology and Health Economics, School of Public Health, The University of Tokyo, 7-3-1 Hongo, Bunkyo-ku, Tokyo 1130033, Japan

${ }^{2}$ Department of Emergency and Critical Care Medicine, Juntendo University

Urayasu Hospital, 2-1-1 Tomioka, Urayasu, Chiba, Japan
}

Non-operative treatment is becoming a treatment option for patients with AAI who have stable vital signs, even if the patients have a large intimal tear and pseudoaneurysm [4].

In recent years, endovascular repair has been rapidly adopted as a feasible treatment modality for patients with AAI because numerous studies of intrinsic disease in the abdominal aorta have shown good clinical results using endovascular stents $[5,6]$. However, the role of endovascular stents in trauma settings and the features of AAI remain unclear.

The present study was performed to investigate the characteristics, treatments, and clinical outcomes among patients with AAI using a Japanese nationwide database.

(C) The Author(s). 2019 Open Access This article is distributed under the terms of the Creative Commons Attribution 4.0 International License (http://creativecommons.org/licenses/by/4.0/), which permits unrestricted use, distribution, and reproduction in any medium, provided you give appropriate credit to the original author(s) and the source, provide a link to the Creative Commons license, and indicate if changes were made. The Creative Commons Public Domain Dedication waiver (http://creativecommons.org/publicdomain/zero/1.0/) applies to the data made available in this article, unless otherwise stated. 


\section{Methods}

\section{Study design and data collection}

This retrospective cohort study was performed using the Japanese Diagnosis Procedure Combination database [7]. The details of the database are described elsewhere [8]. Briefly, the database comprises administrative claims and discharge abstract data from more than 1200 acute-care hospitals in Japan [8]. It also covers approximately $90 \%$ of all tertiary-care emergency hospitals and contains the main diagnosis, primary diagnosis on admission, comorbidities present on admission, and comorbidities diagnosed during each episode of hospitalization recorded using International Classification of Diseases and Related Health Problems, 10th Revision (ICD-10) codes with text data in Japanese. A validation study for the database showed high specificity of recorded diagnoses and high sensitivity and specificity of recorded procedures [9].

\section{Study participants}

Data recorded from 1 July 2010 to 31 March 2017 in the database were used for the present study. We studied patients with a confirmed diagnosis of AAI with emergency admission. We identified diagnoses of AAI with the ICD-10 code S350. We excluded patients who were younger than 18 years of age, died in the emergency room, and underwent both open and endovascular repairs. Eligible patients were divided into those who were treated non-operatively (non-repair group), those who underwent surgery without endovascular treatment (open repair group), and those who underwent endovascular treatment without surgery (endovascular repair group).

\section{Variables and outcomes}

For this study, we examined the following patient background characteristics: age, sex, body mass index $\left(\mathrm{kg} / \mathrm{m}^{2}\right)$, Japan Coma Scale (JCS) score, coexisting injury (head injury, lumbar spine and/or pelvic fracture, bowel injury, splenic injury, and liver and/or biliary tract injury), and modified ICD-10-based Injury Severity Score (modified ICISS) [10]. A high modified ICISS indicates high severity. This score achieved high accuracy (area under the curve, 0.887 ) for mortality prediction among patients with trauma in the database.

Age was categorized into 18 to 49,50 to 64,65 to 79 , and $\geq 80$ years. The JCS score was categorized into four groups: 0 (alert), 1 to 3 (delirium), 10 to 30 (somnolence), and 100 to 300 (coma) points. The JCS score is well correlated with the Glasgow Coma Scale score, and a JCS score of 100 is equivalent to a Glasgow Coma Scale score of 6 to $9[11,12]$.

The primary outcome was in-hospital mortality. The secondary outcomes were 24-h mortality, length of stay, volume of blood transfusion, and major complications.

\section{Statistical analysis}

Continuous variables are presented as medians and interquartile ranges. Categorical variables are presented as numbers and percentages. Baseline characteristics and crude outcomes were compared using the Kruskal-Wallis test for continuous variables with a skewed distribution and the chi-squared test or Fisher's exact test for categorical variables among the non-repair, open repair, and endovascular repair groups.

We examined the numbers and proportions of non-repair, open repair, and endovascular repair from 1 July 2010 to 31 March 2012, from 1 April 2012 to 31 March 2014, from 1 April 2014 to 31 March 2016, and from 1 April 2016 to 31 March 2017.

The two-sided significance level for all tests was $P<$ 0.05. All analyses were performed using Stata/SE version 15 (StataCorp, College Station, TX, USA).

\section{Results}

A total of 238 patients met the inclusion criteria during the study period. Of these, 191 (80.3\%) underwent nonrepair, 20 (8.4\%) underwent open repair, and 27 (11.3\%) underwent endovascular repair (Fig. 1). The numbers and proportions of patients in the non-repair group from July 2010 to March 2012, April 2012 to March 2014, April 2014 to March 2016, and April 2016 to March 2017 were 43 (93.5\%), 60 (75.9\%), 58 (80.6\%), and $30(73.2 \%)$, respectively (Fig. 2$)$. The numbers and proportions of patients in the endovascular repair group during these four periods were $0(0.0 \%), 12(15.2 \%), 8$ (11.1\%), and 7 (17.1\%), respectively.

The patients' baseline characteristics are shown in Table 1. The proportions of patients with lumbar spine and/or pelvic fractures were significantly different among the non-repair, open repair, and endovascular repair groups. There were no significant differences in age, sex, body mass index, consciousness level, coexisting injury except for lumbar spine and/or pelvic fracture, or modified ICISS among the groups.

Interventions and treatments are shown in Table 2. The proportions of patients requiring mechanical ventilation, chest tube drainage, defibrillation, and intravenous infusion (noradrenalin, dobutamine, albumin, and tranexamic acid) were significantly different among the non-repair, open repair, and endovascular repair groups.

The outcomes are shown in Table 3. The crude mortality rate within $24 \mathrm{~h}$ after admission was $18.9 \%$ in the non-repair group, $15.0 \%$ in the open repair group, and $11.1 \%$ in the endovascular repair group $(P=0.74)$. The crude in-hospital mortality rate was $26.2 \%$ in the non-repair group, $35.0 \%$ in the open repair group, and $18.5 \%$ in the endovascular repair group. The median length of stay was 18.0 days in the non-repair group, 20.5 days in the open repair group, and 40.0 days in the endovascular 


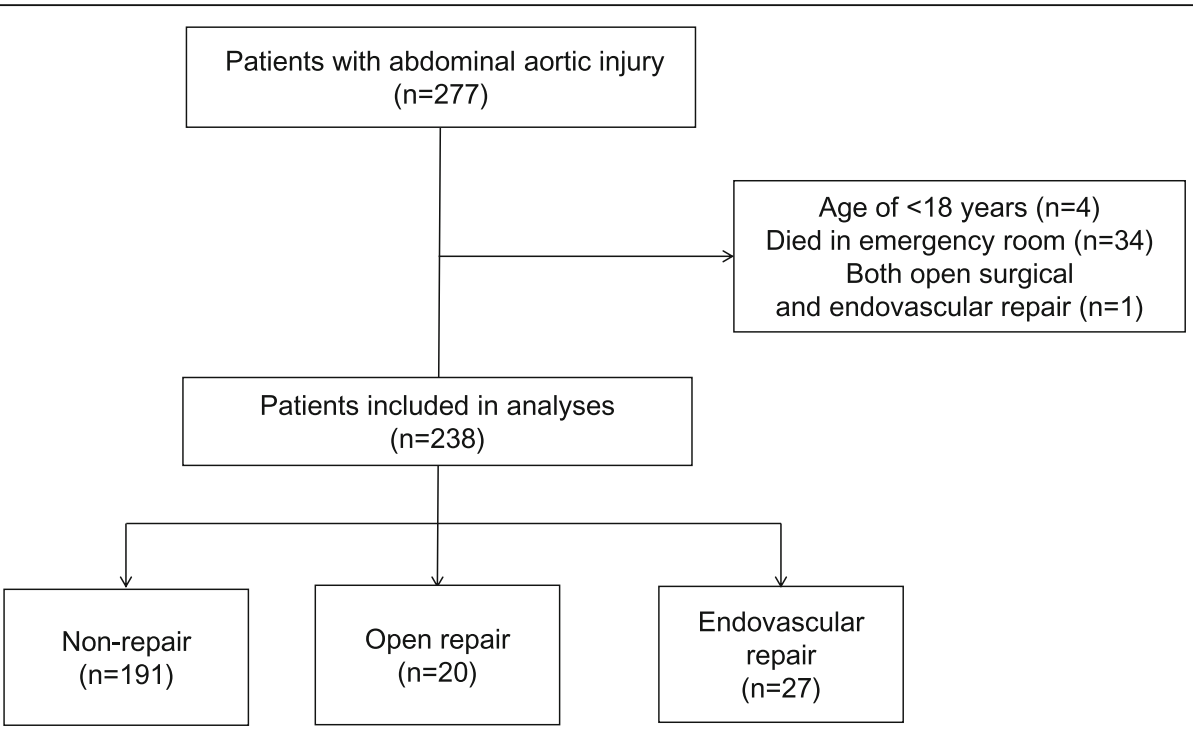

Fig. 1 Study flow diagram of included patients

repair group $(P=0.033)$. The blood transfusion rate was significantly different among the non-repair, open repair, and endovascular repair groups. The median volume of blood transfusion was $1440 \mathrm{ml}$ in the non-repair group, $3610 \mathrm{ml}$ in the open repair group, and $2240 \mathrm{ml}$ in the endovascular repair group $(P=0.002)$. The proportions of pneumonia in the non-repair, open repair, and endovascular groups were $6.3 \%, 10.0 \%$, and $11.1 \%$, respectively $(P=$ 0.58). The proportions of thrombosis or phlebitis in the non-repair, open repair, and endovascular groups were $2.1 \%, 0.0 \%$, and $0.0 \%$, respectively $(P=0.61)$.

\section{Discussion}

The present nationwide cohort study showed no significant differences in in-hospital mortality and major complications among the non-repair, open repair, and endovascular repair groups. However, the length of stay and proportion of blood transfusion showed significant differences.

These results suggest that patients in the open repair and endovascular repair groups had more severe clinical conditions because they were significantly more likely to require mechanical ventilation, chest tube drainage, defibrillation, and intravenous infusion for treatment of AAI. However, they might have also had different injury patterns necessitating other treatments. In-hospital mortality was not different among the non-repair, open repair, and endovascular repair groups.

Treatment choices are affected by the situation, environment, and surgeon. Of course, the AAI grade and injury location also affect treatment decisions.

The endovascular repair group had a prolonged length of stay. This may have been because patients who underwent

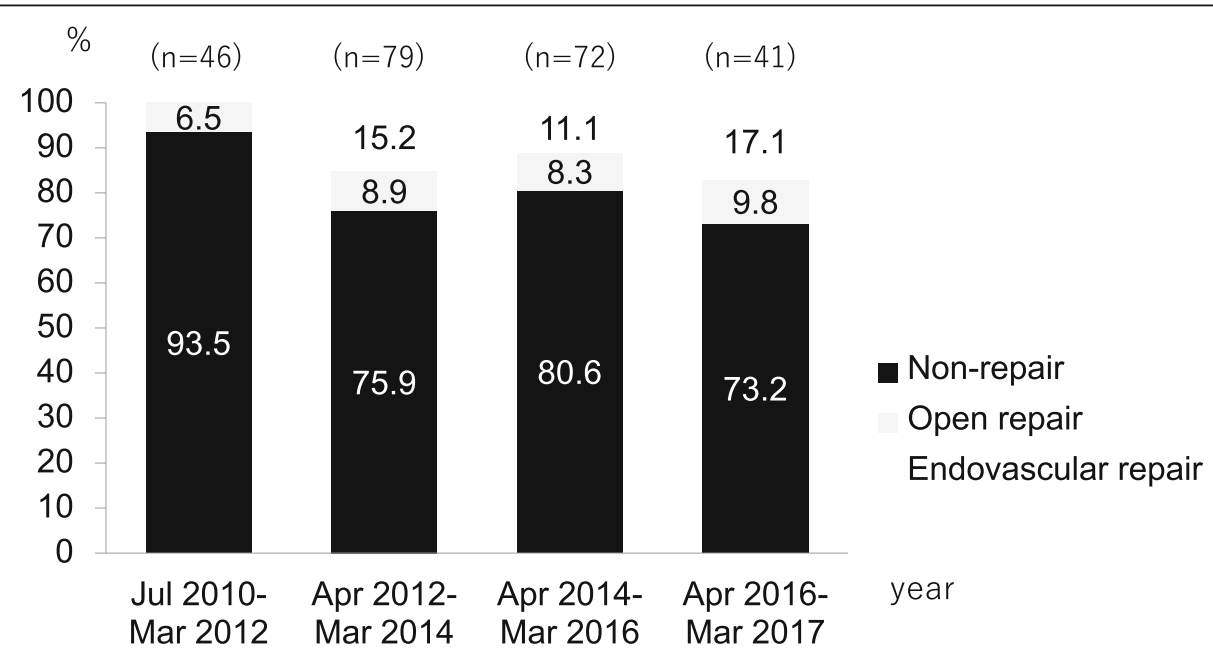

Fig. 2 Changes and proportions of non-repair, open repair, and endovascular repair among patients with abdominal aortic injury in this study cohort 
Table 1 Eligible patients' baseline characteristics

\begin{tabular}{|c|c|c|c|c|}
\hline & Non-repair $(n=191)$ & Open repair $(n=20)$ & Endovascular repair $(n=27)$ & $P$ value \\
\hline Age, years & & & & 0.91 \\
\hline $18-49$ & $41(21.5)$ & $6(30.0)$ & $5(18.5)$ & \\
\hline $50-64$ & $45(23.6)$ & $6(30.0)$ & $7(25.9)$ & \\
\hline $65-79$ & $62(32.5)$ & $5(25.0)$ & $8(29.6)$ & \\
\hline$\geq 80$ & $43(22.5)$ & $3(15.0)$ & $7(25.9)$ & \\
\hline Male sex & $127(66.5)$ & $10(50.0)$ & $13(48.1)$ & 0.082 \\
\hline $\mathrm{BMI}, \mathrm{kg} / \mathrm{m}^{2}$ & $22.2(20.1-24.9)$ & $21.1(19.6-24.4)$ & $20.5(17.7-22.5)$ & 0.076 \\
\hline $\begin{array}{l}\text { Consciousness level } \\
\text { (JCS score) }\end{array}$ & & & & 0.58 \\
\hline 0 & $92(48.2)$ & $7(35.0)$ & $12(44.4)$ & \\
\hline $1-3$ & $34(17.8)$ & $4(20.0)$ & $8(29.6)$ & \\
\hline $10-30$ & $27(14.1)$ & $3(15.0)$ & $4(14.8)$ & \\
\hline $100-300$ & $38(19.9)$ & $6(30.0)$ & $3(11.1)$ & \\
\hline \multicolumn{5}{|l|}{ Co-existing injury } \\
\hline Head injury & $18(9.4)$ & $0(0.0)$ & $3(11.1)$ & 0.32 \\
\hline $\begin{array}{l}\text { Lumbar spine and/or } \\
\text { pelvic fracture }\end{array}$ & $44(23.0)$ & $3(15.0)$ & $13(48.1)$ & 0.016 \\
\hline Small intestine injury & $13(6.8)$ & $1(5.0)$ & $1(3.7)$ & 1.0 \\
\hline Splenic injury & $7(3.7)$ & $1(5.0)$ & $1(3.7)$ & 0.49 \\
\hline $\begin{array}{l}\text { Liver and/or biliary } \\
\text { tract injury }\end{array}$ & $16(8.4)$ & $0(0.0)$ & $1(3.7)$ & 0.50 \\
\hline Modified ICISS & $5.3(4.1-7.1)$ & $4.8(3.5-6.2)$ & $5.9(4.1-7.8)$ & 0.60 \\
\hline
\end{tabular}

Data are presented as number (\%) or median (interquartile range)

BMI body mass index, JCS Japan Coma Scale, ICISS International Classification of Diseases-10-based Injury Severity Score

Table 2 Interventions and treatments among patients undergoing non-repair, open repair, and endovascular repair

\begin{tabular}{|c|c|c|c|c|}
\hline & Non-repair $(n=191)$ & Open repair $(n=20)$ & Endovascular repair $(n=27)$ & $P$ value \\
\hline Ventilator & $64(33.5)$ & $15(75.0)$ & $17(63.0)$ & $<0.001$ \\
\hline Chest tube & $18(9.4)$ & $3(15.0)$ & $8(29.6)$ & 0.013 \\
\hline Tracheostomy & $11(5.8)$ & $3(15.0)$ & $4(14.8)$ & 0.06 \\
\hline $\begin{array}{l}\text { Continuous renal } \\
\text { replacement therapy }\end{array}$ & $9(4.7)$ & $2(10.0)$ & $1(3.7)$ & 0.45 \\
\hline Defibrillator & $4(2.1)$ & $3(15.0)$ & $2(7.4)$ & 0.01 \\
\hline $\begin{array}{l}\text { Extracorporeal } \\
\text { membrane oxygenation }\end{array}$ & $2(1.0)$ & $1(5.0)$ & $0(0)$ & 0.26 \\
\hline \multicolumn{5}{|l|}{ Drugs } \\
\hline Noradrenalin & $31(16.2)$ & $10(50.0)$ & $8(29.6)$ & $<0.001$ \\
\hline Adrenalin & $29(15.2)$ & $5(20.0)$ & $7(25.9)$ & 0.24 \\
\hline Dopamine & $29(15.2)$ & $6(30.0)$ & $8(29.6)$ & 0.066 \\
\hline Dobutamine & $9(4.7)$ & $4(20.0)$ & $1(3.7)$ & 0.036 \\
\hline Albumin & $47(24.6)$ & $15(75.0)$ & $9(33.3)$ & $<0.001$ \\
\hline Tranexamic acid & $42(22.0)$ & $8(40.0)$ & $16(59.3)$ & $<0.001$ \\
\hline
\end{tabular}


Table 3 Outcomes among patients undergoing non-repair, open repair, and endovascular repair

\begin{tabular}{|c|c|c|c|c|}
\hline & Non-repair $(n=191)$ & Open repair $(n=20)$ & Endovascular repair $(n=27)$ & $P$ value \\
\hline \multicolumn{5}{|l|}{ Mortality } \\
\hline Died within $24 \mathrm{~h}$ & $36(18.9)$ & $3(15.0)$ & $3(11.1)$ & 0.74 \\
\hline In-hospital mortality & $50(26.2)$ & $7(35.0)$ & $5(18.5)$ & 0.44 \\
\hline Length of stay, days & $18(3-43)$ & $20.5(4.3-52.8)$ & $40(28-51)$ & 0.033 \\
\hline \multicolumn{5}{|l|}{ Blood transfusion } \\
\hline $\mathrm{RBC}$ & $81(42.4)$ & $17(85.0)$ & $24(88.9)$ & $<0.001$ \\
\hline FFP & 59 (30.9) & $17(85.0)$ & $22(81.5)$ & $<0.001$ \\
\hline Platelet & $30(15.7)$ & $12(60.0)$ & $12(44.4)$ & $<0.001$ \\
\hline $\begin{array}{l}\text { Volume of blood } \\
\text { transfusion, ml }\end{array}$ & $1440(560-3165)$ & 3610 (2085-6865) & $2240(840-4068)$ & 0.002 \\
\hline \multicolumn{5}{|l|}{ Complications } \\
\hline $\begin{array}{l}\text { Hospital-acquired } \\
\text { pneumonia }\end{array}$ & $12(6.3)$ & $2(10.0)$ & $3(11.1)$ & 0.58 \\
\hline Thrombosis/phlebitis & $4(2.1)$ & $0(0.0)$ & $0(0.0)$ & 0.61 \\
\hline
\end{tabular}

Data are presented as number (\%) or median (interquartile range)

$R B C$ red blood cells, FFP fresh frozen plasma

endovascular repair were more likely to have pelvic fractures, which require a longer duration of bed rest. The total hospitalization costs were highest in the endovascular repair group.

Our results showed a higher proportion of lumbar spine and/or pelvic fracture in patients with AAI, which corresponds to the results of previous studies [13, 14]. These fractures are generally caused by high-energy trauma, which affects not only the lumbar spine or pelvis but also the local abdominal aorta. Thus, particular attention should be paid to the abdominal aorta on initial computed tomography imaging for patients with abdominal trauma in the emergency department.

Our results also demonstrated a higher proportion of endovascular repair in patients with AAI who had lumbar spine and/or pelvic fractures. This may have been because endovascular repair can treat both AAI and other types of bleeding.

The present study showed that the proportions of patients undergoing endovascular repair gradually increased from 2010 to 2017, whereas the proportion of patients who underwent no repair decreased (Fig. 2). These results are consistent with those in recent observational studies on thoracic aortic injury $[15,16]$. In the present study, the proportion of open repair was higher in patients with AAI aged 18 to 64 years than in those aged $\geq 65$ years, whereas the proportion of endovascular repair was higher in patients aged $\geq 50$ years than 18 to 49 years (Table 1 ). These trends suggest that the proportions of older patients who undergo endovascular repair and younger patients who undergo open repair are increasing. Endovascular repair can be a good indication for older patients because it is less invasive; however, the long-term outcomes of endovascular repair for young patients remain unknown.
AAI is rarely seen in the clinical setting, and this study therefore provides useful information on the clinical features of patients with AAI. The Society of Vascular Surgery released a clinical practice guideline for thoracic aortic injuries, but a similar consensus regarding AAI has not been reached $[4,17]$. Our results provide useful information that can contribute to the establishment of further consensus.

This study has several limitations. First, the type and degree of AAI, cause of trauma, cause of death, physiological parameters, and laboratory data were not available in the database. Second, no information was available regarding patients who died before reaching the hospital because the database contained only inpatient data. Third, this was a retrospective study, and the recorded diagnoses were less well validated than those in prospective registries. Finally, we evaluated only proven injuries because of the nature of the database.

\section{Conclusions}

In this cohort, the proportion of non-repair for AAI decreased from 2010 to 2017, whereas the proportion of endovascular repair increased. Younger patients were more likely to undergo open repair, whereas older patients were more likely to undergo endovascular repair.

\footnotetext{
Abbreviations

AAl: Abdominal aortic injury; ICD-10: International Classification of Diseases and Related Health Problems, 10th Revision; ICISS: ICD-10-based Injury Severity Score; JCS: Japan Coma Scale
}

\section{Acknowledgements}

Not applicable.

\section{Authors' contributions}

YK conceived this study, analyzed the data, and drafted the manuscript. HM collected and analyzed the data. HY revised the design and manuscript. All authors checked and agreed on the final manuscript. 


\section{Funding}

This study was supported by grants from the Ministry of Health, Labour and Welfare, Japan (H30-Policy-Designated-004 and H29-ICTGeneral-004); the Ministry of Education, Culture, Sports, Science and Technology, Japan (17H04141); and the Japan Agency for Medical Research and Development (AMED). The funders had no role in the execution of this study.

\section{Availability of data and materials}

The datasets used during the current study are available from the corresponding author on reasonable request.

\section{Ethics approval and consent to participate}

This study was approved by the Institutional Review Board of The University of Tokyo Hospital. The requirement for obtaining informed consent from patients was waived because the data sets were anonymous.

\section{Consent for publication}

Informed consent was waived because of the anonymous nature of the data.

\section{Competing interests}

The authors declare that they have no competing interests.

Received: 18 May 2019 Accepted: 16 August 2019

Published online: 27 August 2019

\section{References}

1. Michaels AJ, Gerndt SJ, Taheri PA, Wang SC, Wahl WL, Simeone DM, et al. Blunt force injury of the abdominal aorta. J Trauma. 1996;41: 105-9.

2. Harris DG, Drucker CB, Brenner ML, Sarkar R, Narayan M, Crawford RS. Patterns and management of blunt abdominal aortic injury. Ann Vasc Surg. 2013;27:1074-80

3. Dayama A, Rivera A, Olorunfemi O, Mahmoud A, Fontecha CA, McNelis J. Open and endovascular abdominal aortic injury repair outcomes in polytrauma patients. Ann Vasc Surg. 2017:42:156-61.

4. Charlton-Ouw KM, DuBose JJ, Leake SS, Sanchez-Perez M, Sandhu HK, Holcomb JB, et al. Observation may be safe in selected cases of blunt traumatic abdominal aortic injury. Ann Vasc Surg. 2016;30:34-9.

5. Kurosawa K, Matsumura JS, Yamanouchi D. Current status of medical treatment for abdominal aortic aneurysm. Circ J. 2013;77:2860-6.

6. Tayfur K, Senel Bademci M, Yazman S, Canyigit M. Endovascular approach in isolated abdominal aortic dissections. Vascular. 2018:26:477-82.

7. Matsuda S, Fujimori K, Fushimi K. Development of casemix based evaluation system in Japan. Asian Pac J Dis Manag. 2010:4:55-66.

8. Yasunaga H, Matsui H, Horiguchi H, Fushimi K, Matsuda S. Clinical epidemiology and health services research using the diagnosis procedure combination database in Japan. Asian Pac J Dis Manag. 2013;7:1-2.

9. Yamana H, Moriwaki M, Horiguchi H, Kodan M, Fushimi K, Yasunaga H. Validity of diagnoses, procedures, and laboratory data in Japanese administrative data. J Epidemiol. 2017;27:476-82

10. Wada T, Yasunaga H, Yamana H, Matsui H, Matsubara T, Fushimi K, et al. Development and validation of a new ICD-10-based trauma mortality prediction scoring system using a Japanese national inpatient database. In Prev. 2017;23:263-7.

11. Ono K, Wada K, Takahara T, Shirotani T. Indications for computed tomography in patients with mild head injury. Neurol Med Chir (Tokyo). 2007:47:291-7.

12. Shigematsu $\mathrm{K}$, Nakano $H$, Watanabe $\mathrm{Y}$. The eye response test alone is sufficient to predict stroke outcome--reintroduction of Japan Coma Scale: a cohort study. BMJ Open. 2013;3. https://doi.org/10.1136/ bmjopen-2013-002736.

13. Shalhub S, Starnes BW, Brenner ML, Biffl WL, Azizzadeh A, Inaba K, et al. Blunt abdominal aortic injury: a Western Trauma Association multicenter study. J Trauma Acute Care Surg. 2014;77:879-85 discussion 885.

14. de Mestral C, Dueck AD, Gomez D, Haas B, Nathens AB. Associated injuries, management, and outcomes of blunt abdominal aortic injury. J Vasc Surg. 2012;56:656-60.

15. Tagami T, Matsui $H$, Horiguchi $H$, Fushimi K, Yasunaga H. Thoracic aortic injury in Japan--nationwide retrospective cohort study. Circ J. 2015;79:55-60.
16. Hasjim BJ, Grigorian A, Barrios C Jr, Schubl S, Nahmias J, Gabriel V, et al. National trends of thoracic endovascular aortic repair (TEVAR) versus open thoracic aortic repair (OTAR) in pediatric blunt thoracic aortic injury. Ann Vasc Surg. 2019. https://doi.org/10.1016/j.avsg.2018.12.094. Epub ahead of print.

17. Lee WA, Matsumura JS, Mitchell RS, Farber MA, Greenberg RK Azizzadeh A, et al. Endovascular repair of traumatic thoracic aortic injury: clinical practice guidelines of the Society for Vascular Surgery. J Vasc Surg. 2011;53:187-92.

\section{Publisher's Note}

Springer Nature remains neutral with regard to jurisdictional claims in published maps and institutional affiliations.
Ready to submit your research? Choose BMC and benefit from:

- fast, convenient online submission

- thorough peer review by experienced researchers in your field

- rapid publication on acceptance

- support for research data, including large and complex data types

- gold Open Access which fosters wider collaboration and increased citations

- maximum visibility for your research: over $100 \mathrm{M}$ website views per year

At $\mathrm{BMC}$, research is always in progress.

Learn more biomedcentral.com/submissions 